\title{
Erratum to: Quantifying the health impacts of ambient air pollutants: methodological errors must be avoided
}

\author{
Peter Morfeld • Thomas C. Erren
}

Published online: 17 May 2016

(c) Swiss School of Public Health (SSPH+) 2016

\section{Erratum to: Int J Public Health}

\section{DOI 10.1007/s00038-015-0766-8}

Unfortunately, in the original publication of the Editorial, the second author name was missing from the authorship. The author name and affiliation are included here and the original publication is corrected as well.

The online version of the original article can be found under doi:10.1007/s00038-015-0766-8.

P. Morfeld ( $\square)$

Institute for Occupational Epidemiology and Risk Assessment

(IERA) of EvonikIndustries, Rellinghauser Str. 1-11,

45128 Essen, Germany

e-mail: peter.morfeld@evonik.com

P. Morfeld · T. C. Erren

Institute and Policlinic for Occupational Medicine,

Environmental Medicine and Prevention Research of Cologne

University, Kerpener Str. 62, 50937 Cologne, Germany

e-mail: Tim.Erren@Uni-Koeln.de 